\title{
Linear enamel hypoplasia due to serious systemic infection
}

Sir,

Linear enamel hypoplasia (LEH) is a developmental disturbance of the enamel resulting in clinically visible horizontal defects in enamel that are present on eruption of the tooth. ${ }^{[1]}$ It is accepted that LEHs, a specific type of enamel thickness deficiency, are related to periodic physiological disruptions to enamel matrix secretion during times when the teeth are developing. ${ }^{[1]}$ Thus, LEHs are treated as general indicators of metabolic stress. Because the disruptions that cause LEHs affect only the portion of the crown that is in the process of forming, determining their locations allows researchers to reconstruct chronologies of stressful events. ${ }^{[2]} \mathrm{LEH}$ is endemic in many countries of the world (with a prevalence of $38 \%$ in some populations), and is commonly reported in association with disease of childhood. ${ }^{[3]}$ Although the pathophysiology of LEH is undetermined, many authors have suggested the synergistic action of malnutrition and infection as the most probable causative factors. ${ }^{[2]}$ A strong evidence is also present that states that the factor responsible for hypoplasia of the linear type also predisposes to dental caries. ${ }^{[2]}$

A patient aged 28 years reported to the Department of Periodontology with a chief complaint of bleeding gums since 4 months. On intra-oral examination, apart from plaque and calculus that was the etiologic factor for gingival bleeding, a pronounced linear line or band was noticed on the middle portion of the crown of the maxillary and mandibular anterior teeth [Figure 1]. The linear line or band was seen prominently on both the labial and the lingual aspects of the maxillary and mandibular incisors, canines and first molars. Family history was noncontributory. The patient reported that his deciduous teeth did not have any lines or bands. The patient further stated that the linear line or band was becoming more evident over the years. Past medical history further revealed that the patient had survived a serious, life-threatening infection during $3^{\text {rd }}$ or $4^{\text {th }}$ year of his life. Intra-oral periapical radiograph of the maxillary anterior region showed differences in radioopacity between the two areas of the teeth separated by a thin linear line [Figure 2]. The patient had lost his right mandibular first molar due to dental caries. Based on the patient's history and clinical presentation, a diagnosis of LEH was made. Oral prophylaxis was completed to solve the patient's presenting problem. The patient was not willing to undergo restorative treatment for LEH.

Supplementing milk with vitamins during the first several years of life leads to reduction in the prevalence of $\mathrm{LEH}$, a condition that may be associated with future development of dental caries. There are equivocal findings concerning the value of using good dietary habits and

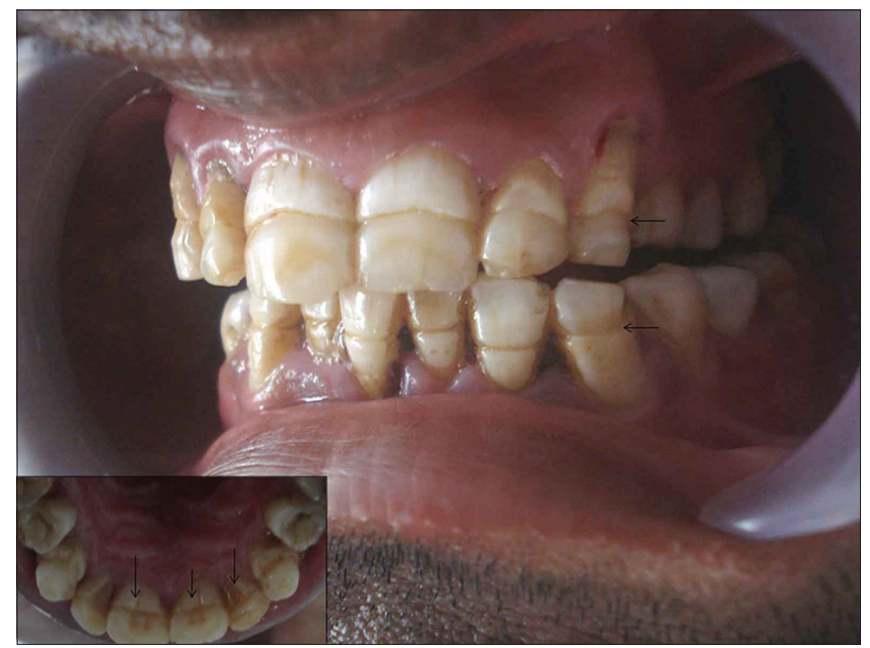

Figure 1: Clinical image of a patient with linear enamel hypoplasia (LEH) seen on maxillary and mandibular anteriors. Inset shows the band or line of LEH on the palatal aspect

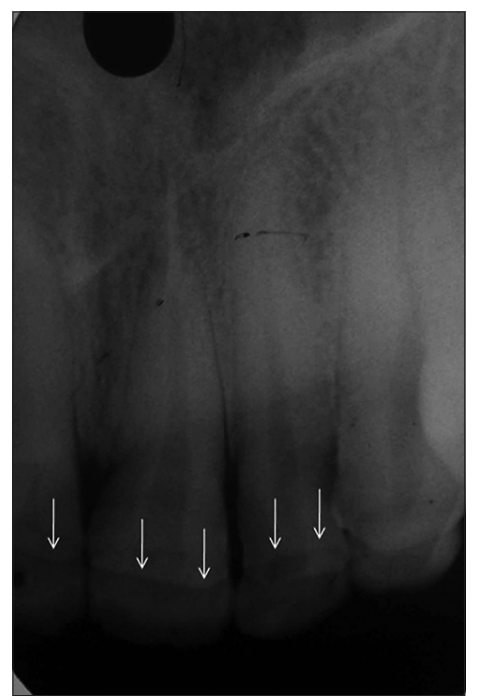

Figure 2: Intra-oral periapical radiograph of the maxillary anterior teeth showing the differences in radio-opacity between the two areas of the teeth separated by a thin linear line

a need for development of educational, nutritional and prevention programs targeting mothers and infants. ${ }^{[4]}$

Vishwas Anjum, Srinivas Sulugodu Ramachandra, Jithendra Kajoor Dayakara

Department of Periodontology, Kanti Devi Dental College and Hospital, Mathura, Uttar Pradesh, India

Address for correspondence: Dr. Anjum Vishwas, Department of Periodontology, Kanti Devi Dental College and Hospital, Delhi-Agra National Highway \#2, Mathura, P.O. Chattikhara, Uttar Pradesh, India. E-mail: anjum_v@yahoo.com 


\section{REFERENCES}

1. Ritzman TB, Baker BJ, Schwartz GT. A fine line: A comparison of methods for estimating ages of linear enamel hypoplasia formation. Am J Phys Anthropol 2008;135:348-61.

2. King T, Humphrey LT, Hillson S. Linear enamel hypoplasias as indicators of systemic physiological stress: Evidence from two known age-at-death and sex populations from postmedieval London. Am J Phys Anthropol 2005;128:547-59.

3. Guatelli-Steinberg D, Larsen CS, Hutchinson DL. Prevalence and the duration of linear enamel hypoplasia: A comparative study of Neandertals and Inuit foragers. J Hum Evol 2004;47:65-84.
4. Ismail AI. The role of early dietary habits in dental caries development Spec Care Dentist 1998;18:40-5.

\begin{tabular}{|l|l|}
\hline \multicolumn{2}{|c|}{ Access this article online } \\
\hline Quick Response Code: & Website: \\
\hline & www.ejgd.org \\
\hline & \\
\hline
\end{tabular}

Staying in touch with the journal

1) Table of Contents (TOC) email alert Receive an email alert containing the TOC when a new complete issue of the journal is made available online. To register for TOC alerts go to www.ejgd.org/signup.asp.

\section{2) RSS feeds}

Really Simple Syndication (RSS) helps you to get alerts on new publication right on your desktop without going to the journal's website. You need a software (e.g. RSSReader, Feed Demon, FeedReader, My Yahoo!, NewsGator and NewzCrawler) to get advantage of this tool. RSS feeds can also be read through FireFox or Microsoft Outlook 2007. Once any of these small (and mostly free) software is installed, add www.ejgd.org/rssfeed.asp as one of the feeds. 